\title{
Tackling aquatic invasions: risks and opportunities for the aquarium fish industry
}

\author{
Andrew L. Chang · Judah D. Grossman - Teresa Sabol Spezio · \\ Heidi W. Weiskel · Julia C. Blum · Jennifer W. Burt · Adrianna A. Muir · \\ Jonah Piovia-Scott $\cdot$ Kari E. Veblen · Edwin D. Grosholz
}

Received: 3 December 2007 / Accepted: 22 May 2008/Published online: 18 July 2008

(C) The Author(s) 2008

\begin{abstract}
The aquarium trade is an important and rapidly growing vector for introduced species in the United States. We examined this vector by surveying pet stores in the San Francisco Bay-Delta region to compile a list of aquarium fish species commonly stocked. We identified which of these species might be able to survive in the Bay-Delta, and investigated store representatives' knowledge and attitudes about biological invasions. A restrictive analysis using
\end{abstract}

Electronic Supplementary Material The online version of this article (doi:10.1007/s10530-008-9292-4) contains supplementary material, which is available to authorized users.

A. L. Chang · H. W. Weiskel · E. D. Grosholz

Department of Environmental Science and Policy, University of California, One Shields Avenue, Davis, CA 95616, USA

A. L. Chang $(\square)$

Bodega Marine Laboratory, PO Box 247, Bodega Bay, CA 94923, USA

e-mail: andchang@ucdavis.edu

J. D. Grossman · J. W. Burt · K. E. Veblen

Department of Plant Sciences, University of California,

One Shields Avenue, Davis, CA 95616, USA

\section{T. S. Spezio}

Department of History, University of California, One Shields Avenue, Davis, CA 95616, USA

J. C. Blum - A. A. Muir · J. Piovia-Scott Department of Evolution and Ecology, University of California, One Shields Avenue, Davis, CA 95616, USA conservative estimates of fish temperature tolerances and environmental conditions found that the local aquarium trade includes 5 fish species that can survive in a temperate system such as the Bay-Delta. Under more inclusive parameters, up to 27 fish species met the criteria for survival in the Bay-Delta. We further explored these results by comparing potential invader incidence between different types of stores. In the more restrictive analysis, three national retail chains stocked significantly more potentially invasive species than independent aquarium stores, but there was no difference in the more inclusive analysis. A significantly higher percentage of fish taxa were easily identifiable and well-labeled in chain stores than in independent stores. Most aquarium store representatives indicated willingness to take action to reduce the threat of traderelated introductions, although chain store employees were more willing to assign responsibility for reducing this threat to the aquarium industry than were independent store employees. Management efforts for this vector should focus on (a) improving labeling and identification of fish species in stores, (b) expanding the often spotty data on fish physiological tolerances, especially for saltwater species, (c) educating customers and store employees about the risks posed by pet release, and (d) providing better options for responsible disposal of unwanted fish.

Keywords Biological invasion - Aquarium · San Francisco Bay · Bay-Delta · Fish . Temperature tolerance $\cdot$ Non-indigenous . 
Vectors · Ornamental · Predicting invaders ·

Risk assessment

\section{Introduction}

Invasive species are a growing source of ecological and economic harm worldwide (Chapin et al. 2000; Sala et al. 2000; Worm et al. 2006; Lotze et al. 2006). Non-indigenous organisms are transported throughout the United States via international and domestic trade at an ever-increasing rate, making the introduction of new species inevitable (Jenkins 1996; Levine and D'Antonio 2003). The aquarium trade represents one of five major avenues for introduction of non-indigenous aquatic species (Ruiz et al. 1997) and has been linked to over 150 species invading natural ecosystems around the world (Fuller 2003; Siguan 2003; Padilla and Williams 2004). We examined the retail trade in ornamental fishes, which are the centerpiece of the rapidly growing aquarium industry and consist largely of Indo-West Pacific and South American tropical species marketed and sold in other regions of the world (Chapman et al. 1997).

Our study considers both biological and sociological aspects of the aquarium trade to assess its potential as a vector for human-mediated introductions of non-native fish species. The risk posed by an invasion vector has both a biological component (the ability of species to establish self-sustaining populations) and a human component (the delivery of species to the new habitat), so an assessment of invasion risk must consider both elements. Since local environmental conditions, trade practices, and consumer preferences for particular fish species are subject to regional variation, the aquarium traderelated invasion risk profile likely exhibits substantial geographic variation. Therefore, we focused our research on our local area, the San Francisco BayDelta, and we offer our work here both as an assessment of one particular location and as a model for future studies investigating the role of the commercial pet industry in biological invasions.

The San Francisco Bay-Delta region (henceforth, Bay-Delta) in California, U.S.A., is a major Pacific coast trade hub and one of the largest estuarine and freshwater ecosystems in North America. The BayDelta includes over $1500 \mathrm{~km}^{2}$ of aquatic habitat of varying water temperatures and salinities and serves as a critical juncture between the Pacific Ocean and a watershed comprising 40 percent of the state of California (Conomos 1979). A heavily urbanized area, the Bay-Delta is subject to ever-increasing rates of invasion by non-native species (Cohen and Carlton 1995). Over 7 months (December 2004-June 2005), we determined which locally-sold aquarium species might be potential invaders in the Bay-Delta by first conducting an extensive inventory of aquarium fish stocked in Bay-Delta stores, then identifying which species might be able to survive in the Bay-Delta by comparing fish physiological tolerances to regional environmental parameters. We examined the risk posed by different segments of the aquarium industry by analyzing where potential invaders were sold and by investigating in-store practices that might mitigate risk such as product labeling and employee awareness of invasive species. We specifically considered both independent and chain stores, two major types of retail outlet in the aquarium trade. While our study did not consider sales volume or the frequency of releases into waterways, we did describe which species are for sale, determine which might survive in local waterways, and explore the vector's social dynamics, which are key first steps in determining the importance of this invasion pathway.

\section{Methods}

Inventory of aquarium fish for sale in the Bay-Delta

We identified 168 stores that sold aquarium fish in the Bay-Delta using a keyword search of online business directory listings (Verizon 2004; Yahoo! 2004). We searched for stores selling items related to "fish" and/or "aquarium" in the greater San Francisco Bay-Delta area and called each store to confirm that they sold aquarium fish. Based on proximity to freshwater or saltwater parts of the Bay-Delta system, we separated the geographical area under study into three regions (Fig. 1). We classified each store as either an independent or a chain store and then randomly selected and surveyed nine independent and nine chain stores per region for a total of 54 stores. Individually owned and operated stores were classified as independent, while retailers that were part of a chain with multiple 


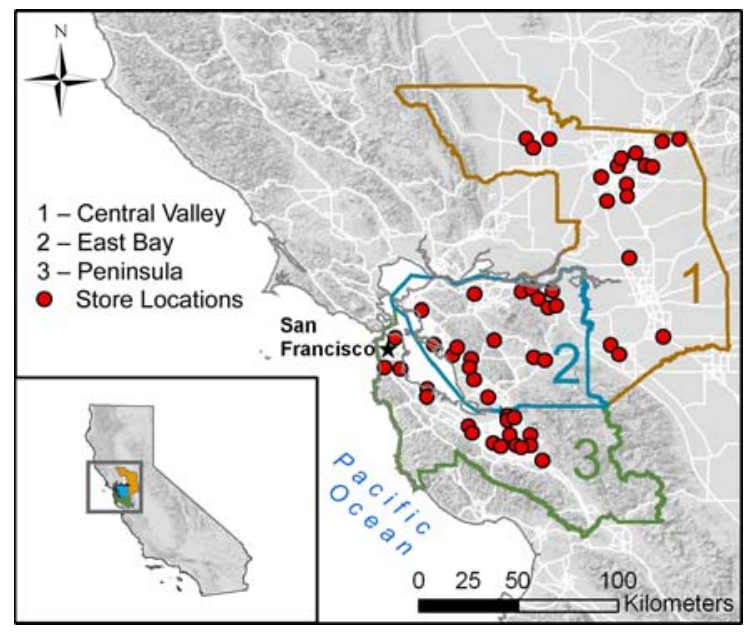

Fig. 1 Regional divisions and locations of stores visited during the store survey in the San Francisco Bay-Delta

retail outlets and centralized management were classified as chain stores. The nine chain stores per region were equally divided among the three possible chain stores: a large international general discount retailer with a freshwater aquarium pet section (hereafter referred to as General Discount Chain), Pet Chain A (a large international specialty retailer of pet supplies and services with a mostly freshwater aquarium pet section), and Pet Chain B (a large national specialty retailer of pet supplies and services with an aquarium pet section of both salt and freshwater species). We conducted an exhaustive inventory of fish stocked in all 54 stores, generating an extensive, representative listing of aquarium fish offered for sale throughout the BayDelta. For each store, we obtained verbal permission to conduct our survey from a manager or supervisor before starting (none of the stores we visited declined to give permission for the study). We then recorded the store's last stocking date, and for each fish tank recorded: (1) species listed on the tank, (2) species present in the tank, and (3) additional labeling information where available. When possible, we identified each organism to species level using Axelrod et al. (1995) and Burgess (2000) as references. The same team of three observers (A. L. Chang, J. D. Grossman, H. W. Weiskel) visited each store to reduce observer bias, with frequent crosschecking of identifications in the store both with other observers and with store representatives to ensure accurate species identification.
Analysis of invasion potential of aquarium fish for sale in the Bay-Delta

We developed a model to assess the invasion potential of aquarium fish by comparing temperature and salinity requirements of aquarium fish found in our inventory to environmental data for the BayDelta region. We used FishBase, a publicly-available database (Froese and Pauly 2005), to determine temperature and salinity requirements for each aquarium fish we could identify to species level during our inventory. The minimum temperature tolerance limit is of particular interest because the aquarium trade generally focuses on tropical species, so cold winter temperatures would likely be the limiting factor for survival of most aquarium fish in the temperate Bay-Delta system (P. Moyle pers. comm.). Precise temperature tolerances are not well known for most saltwater species, so we used numerical temperature data for freshwater species and FishBase's somewhat broader climatic classifications for saltwater species. Climatic categories are temperate, subtropical, and tropical, corresponding to minimum temperature tolerances of 0-10, 10-20, and over $20^{\circ} \mathrm{C}$, respectively (Froese and Pauly 2005).

We then characterized two regions in the BayDelta that consistently differed in salinity based on U.S. Geological Survey (USGS) records: marine (average salinity greater than $30 \mathrm{ppt}$ ) and freshwater (average salinity less than $2 \mathrm{ppt}$ ) (USGS 2006). We excluded the brackish region of the Bay-Delta since few fish sold in the aquarium trade are categorized as brackish or live predominantly in brackish regions. Exact salinity tolerance limits for aquarium fish species are seldom known, but many species classified as either "freshwater" or "saltwater" have reported salinity tolerance ranges that would appear to let them live in brackish waters. Therefore, our exclusion of brackish habitat from consideration in this study means that our conclusions are a conservative estimate of the overall invasion potential of fish species in the aquarium trade.

We defined a "potentially invasive" fish as one that could survive in the Bay-Delta according to available physiological and environmental data. Although a non-native species must successfully pass through numerous steps to establish a population in a new region (in addition to surviving, it must first be transported to the region and then also reproduce), we 
focused on survival because the greatest amount of data was available to evaluate this portion of the invasion process for aquarium fish. As low temperature tolerance is assumed to be a major limiting factor in fish survival in the Bay-Delta, we inferred that introduced fish might move to more favorable locations during cooler seasons. We therefore chose the warmest temperature in a salinity region during winter (i.e. the warmest minimum temperature) as our environmental criterion for determining survival potential. We examined winter temperatures throughout the Bay-Delta using USGS water quality data collected over 10 years (1996-2005) at $1 \mathrm{~m}$ depth in mid-channel throughout the Bay-Delta system along a transect from the Sacramento River to the Golden Gate Bridge (USGS 2006). The warmest minimum temperature for the freshwater zone $(<2 \mathrm{ppt})$ was $8.8^{\circ} \mathrm{C}$ and the warmest minimum temperature for the saltwater zone $(>30 \mathrm{ppt})$ was $10.2^{\circ} \mathrm{C}$.

Preliminary examination of model results suggested that we were underestimating the invasion potential for aquarium fish because these criteria failed to include three non-native species known to be established in the Bay-Delta (Table 2). Because the USGS data represent mid-channel (i.e. not shoreline) temperatures throughout the Bay-Delta system, they do not capture the presence of temperature refugia such as power plant effluents or lagoons that may be the warmest locations in the Bay-Delta during the coldest times of year. Likewise, reported values for fish physiological tolerances are unlikely to be fully representative of a species' tolerances, given intraspecific variation and our incomplete knowledge of temperature limits for many species. We therefore modified our original, restrictive model (Colder Scenario) for both freshwater and saltwater fish to generate a more inclusive Warmer Scenario. Under the Colder Scenario for freshwater fish, we compared the lowest recorded temperature tolerance for each fish species (Froese and Pauly 2005) to the warmest minimum temperature recorded in the freshwater region $\left(8.8^{\circ} \mathrm{C}\right.$; USGS 2006). In the Warmer Scenario, we adjusted the warmest minimum temperature upward $3^{\circ} \mathrm{C}$, while fish temperature tolerances were adjusted downward $3^{\circ} \mathrm{C}$. Although this scenario may be more inclusive in terms of identifying potential fish invaders, it is more likely to realistically reflect the confluence of actual fish temperature tolerances and environmental conditions (P. Moyle pers. comm.).
Similarly, we constructed Colder and Warmer Scenarios for saltwater fish based on the warmest minimum temperature found in the saltwater zone of the Bay-Delta $\left(10.2^{\circ} \mathrm{C}\right)$. Because winter water temperatures in the Bay-Delta often fall below $10^{\circ} \mathrm{C}$, we used FishBase's temperate classification (lower temperature limit of $0-10^{\circ} \mathrm{C}$ ) as the criterion for determining survivorship of saltwater fish in the Colder Scenario and the subtropical classification (lower temperature limit of $10-20^{\circ} \mathrm{C}$ ) as the relevant criterion for the Warmer Scenario.

Statistical analysis

We used our store inventory data to perform two analyses. First, we tested for differences in the number of potentially invasive fish sold in each store among geographical regions and store types. Second, we tested for differences among regions and store types with regard to: (1) the percentage of correctly labeled fish taxa in each store and (2) the percentage of fish taxa in each store that we were able to identify to species level. For each analysis, we performed ANOVA as well as ANCOVA using the total number of taxa identified to species level in each store as a covariate. This approach allowed us to account for the effect of more diverse store inventories, as one might expect a greater number of potential invaders to be found in stores with a greater total number of species (i.e. a sampling effect).

To meet the assumptions of normality and homogeneity of variances in the first analysis, we performed a $\log (x+1)$ transformation on the data where necessary, and in some cases also weighted the ANOVA or ANCOVA using the reciprocal of the variance. In addition, four extreme values in the Colder Scenario data were winsorized to the $5 \%$ and 95\% levels to meet the assumption of normality before running the ANOVA and ANCOVA (Tukey 1962). For all analyses, differences between levels within a factor were detected using least-squares means comparisons. All analyses were performed using the SAS 9.1.2 (SAS Institute Inc. 2005).

Telephone survey of store representatives in the Bay-Delta

We developed a telephone survey to investigate the level of knowledge regarding invasive species among Bay-Delta aquarium store representatives and to 
explore their willingness to address potential threats posed by invasive species. The survey was conducted in July 2005. Using the same list of stores that we identified as selling aquarium fish for our store inventory, we randomly selected and telephoned 114 stores that were not visited during the store inventory. A total of 30 stores (12 chain stores and 18 independent stores) participated in the telephone survey (26.3\% response rate).

Our survey consisted of 17 multi-part, closed-ended questions with opportunity for further comment afterwards. We asked to speak with managers or employees who dealt specifically with aquarium fish at the highest responsibility level possible. The survey was designed to minimize response bias, with survey topics progressing from general to specific. We measured respondents' awareness of invasive species using several different questions that addressed knowledge of the term "invasive species" and perception of invasive species as an environmental problem. To measure respondents' sense of responsibility for preventing introductions of potentially invasive fish species, we asked about the aquarium trade's role in the spread, prevention, and introduction of invasive species. We also questioned respondents about their own involvement in the aquarium trade and their assessment of consumer behavior regarding aquarium fish. Finally, to measure willingness to alter behavior, we asked respondents to indicate whether they would be willing to sell alternative species that would not be potentially invasive.

Analysis of store representatives' knowledge and attitudes

We tested for differences in respondents' knowledge of invasions (awareness), sense of the industry's responsibility regarding invasions, and willingness to alter behavior based on the respondents' store type (independent or chain) and level of involvement in the aquarium trade. We first examined answers to groups of questions addressing awareness and responsibility, respectively, using principal component analyses. We evaluated the principal components using ANCOVA to determine whether store type and expertise predicted awareness of invasive species, and whether store type, expertise, and awareness of invasive species predicted the respondents' assignment of responsibility and their willingness to take action regarding invasive species. Our covariate was an index of the respondents' expertise in the aquarium industry that we created by combining answers to questions that asked whether the respondent owned an aquarium at home and whether s/he bred or traded fish as a hobby. We also tested for differences between independent and chain store respondents' willingness to assign responsibility to different aquarium trade stakeholders. We supplemented these analyses with more specific examinations of responses to individual survey questions using contingency tables evaluated with Fisher's exact test. All analyses were performed in SAS 9.1.2 (SAS Institute Inc. 2005).

\section{Results}

Inventory and analysis of aquarium fish for sale

We observed 1009 unique fish taxa in the 54 stores surveyed and were able to identify 867 of these to species level, comprising 432 freshwater, 23 brackish and 412 marine species. Independent stores as a group had the highest average number of species, with an average of 100.2 species per store, while the General Discount Chain had the fewest, at 34.1 species per store (Table 1). The General Discount Chain sold

Table 1 Average store sizes (in total gallons per store) and average number of species per store identified during store inventory survey

\begin{tabular}{lcccccc}
\hline Store type & $\begin{array}{l}\text { Average } \\
\text { number } \\
\text { of gallons }\end{array}$ & $\begin{array}{l}\text { Median } \\
\text { number } \\
\text { of gallons }\end{array}$ & $\begin{array}{l}\text { Range } \\
\text { of gallons }\end{array}$ & $\begin{array}{l}\text { Average number } \\
\text { of freshwater } \\
\text { species }\end{array}$ & $\begin{array}{l}\text { Average number } \\
\text { of saltwater } \\
\text { species }\end{array}$ & $\begin{array}{l}\text { Average total } \\
\text { number } \\
\text { of species }\end{array}$ \\
\hline Independent & 3639.4 & 2663 & $485-11446$ & 62.9 & 34.8 & 100.2 \\
Chain (all) & 1092.7 & 1101 & $250-2240$ & 57.6 & 4.6 & 0 \\
General Discount Chain & 265.6 & 270 & $250-260$ & 32.2 & 0.6 & 34.7 \\
Pet Chain A & 1679.3 & 1750 & $1018-2225$ & 81.4 & 13.2 & 83.6 \\
Pet Chain B & 1333.2 & 1250 & $660-2240$ & 59 & 74.1 \\
\hline
\end{tabular}


exclusively freshwater fish whereas Pet Chain A sold saltwater fish in addition to freshwater fish in 5 out of 9 stores, but any one of those 5 stores had at most 2 saltwater taxa. One independent store sold only saltwater fish. All other stores sold both freshwater and saltwater fish. Of these species, we found that under the Colder Scenario, 3 of the freshwater and 2 of the saltwater fish species could potentially survive if released into the Bay-Delta (Table 2). In the Warmer Scenario, these numbers increased to 9 freshwater and 18 saltwater species, respectively (Table 2). All 3 of the freshwater species identified by the Colder Scenario and 3 additional freshwater species identified by the Warmer Scenario have already been introduced to the Bay-Delta (Fig. 2), although only one of these introductions (the goldfish Carassius auratus) was the result of the aquarium industry; the others were introduced for angling or mosquito control purposes (Moyle 2002, Moyle pers. comm.). None of the saltwater fish identified as potentially invasive by the Colder and Warmer Scenarios are currently established in the Bay-Delta.

Our results comparing store types (chain versus independent) indicate that potentially invasive fish are sold in nearly all chain and independent stores. In the Colder Scenario, the chain store inventories had a significantly greater number of potential invaders compared to independent store inventories $\left(\mathrm{F}_{1,42}=\right.$ 9.78, $p=0.0032$ ), with Pet Chain A offering the greatest number of potentially invasive fish for sale

Table 2 Non-native ornamental fish species present in stores during this survey and identified under the Colder and Warmer Scenarios as having the potential to survive in the San Francisco Bay-Delta

\begin{tabular}{|c|c|c|}
\hline & Colder Scenario & Warmer Scenario \\
\hline Freshwater species & $\begin{array}{l}\text { Goldfish (Carassius auratus)* } \\
\text { Koi (Cyprinus carpio)* } \\
\text { Rosy red minnow (Pimephales promelas)* }\end{array}$ & $\begin{array}{l}\text { Goldfish (Carassius auratus)* } \\
\text { Koi (Cyprinus carpio)* } \\
\text { Rosy red minnow (Pimephales promelas)* } \\
\text { Western mosquitofish (Gambusia affinis)* } \\
\text { Channel catfish (Ictalurus punctatus)* } \\
\text { Blue catfish (Ictalurus furcatus)* } \\
\text { Dojo loach (Misgurnus anguillicaudatus) } \\
\text { Bull rout (Myoxocephalus scorpius) } \\
\text { Garra pingi (Garra pingi pingi) }\end{array}$ \\
\hline Saltwater species & $\begin{array}{l}\text { Red Scorpionfish (Rhinopias argolipa) } \\
\text { Yasha Hase goby (Stonogobiops yasha) }\end{array}$ & $\begin{array}{l}\text { Red Scorpionfish (Rhinopias argolipa) } \\
\text { Yasha Hase goby (Stonogobiops yasha) } \\
\text { Flying Gurnard (Dactylopterus volitans) } \\
\text { Sergeant Major (Abudefduf saxatilis) } \\
\text { Scrawled Cowfish (Acanthostracion quadricornis) } \\
\text { Orange Filefish (Aluterus schoepfi) } \\
\text { Clown goby (Microgobius gulosus) } \\
\text { Porcupine pufferfish (Diodon holocanthus) } \\
\text { Red grouper (Epinephilus morio) } \\
\text { Banded Cat Shark (Halaelurus lineatus) } \\
\text { Sargassumfish (Histrio histrio) } \\
\text { Western Jumping blenny (Lepidoblennius marmoratus) } \\
\text { Bigeye squirrelfish (Myripristis jacobus) } \\
\text { Green Chromis Damsel (Chromis viridis) } \\
\text { White angelfish (Chaetodipterus faber) } \\
\text { Pygmy angelfish (Centropyge argi) } \\
\text { Blueface angelfish (Chaetodontoplus personifer) } \\
\text { Harlequin tuskfish (Choerodon fasciatus) }\end{array}$ \\
\hline
\end{tabular}

* Non-native species already known to have established in the Bay-Delta 
Fig. 2 Magnitude of the aquarium trade in the San Francisco Bay-Delta region. The number of nonnative aquarium species currently found in the San Francisco Bay-Delta region is affected by the size of the ornamental fish trade, the number of species sold regionally, the physiological and environmental parameters of the system, number of releases (incidental or intentional) and the species that have been correctly identified in the system

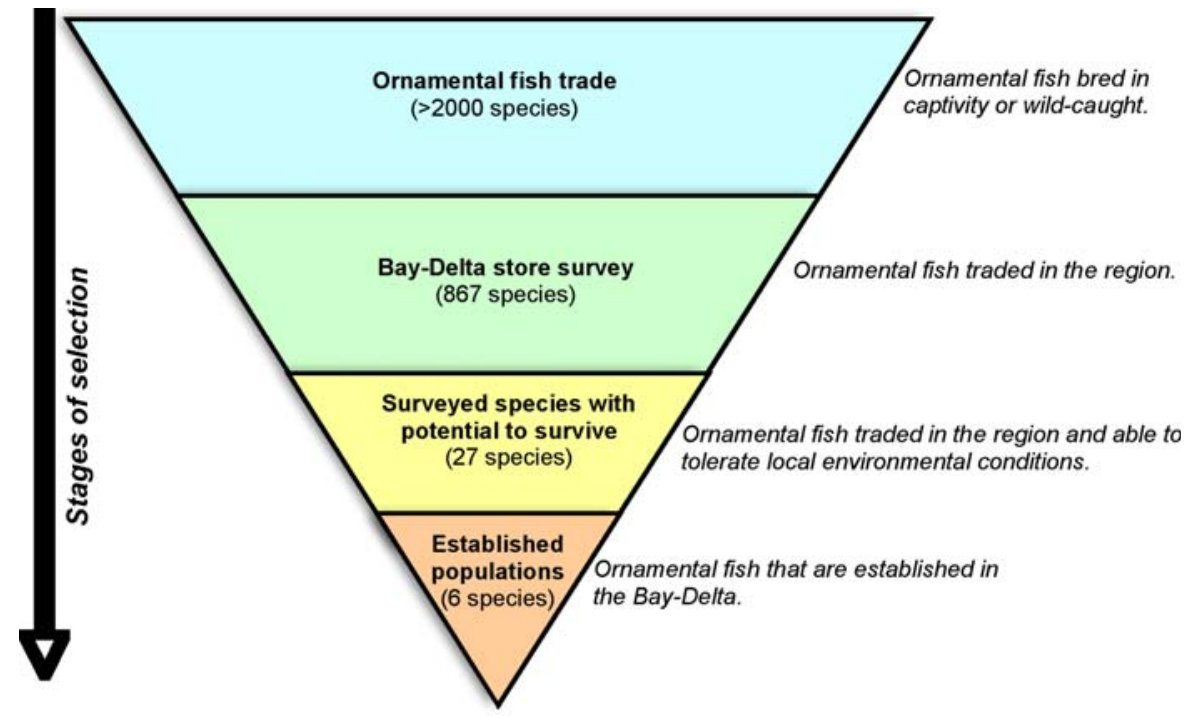

Table 3 Weighted ANOVA results from store survey under the Colder and Warmer Scenarios

\begin{tabular}{lrrrr}
\hline Source & DF & \multicolumn{1}{l}{ MS } & $p$-value \\
\hline Colder Scenario & & & & \\
Region & 2 & 0.991 & 0.87 & 0.4277 \\
Store type & 1 & 11.172 & 9.78 & $\mathbf{0 . 0 0 3 2}$ \\
Region $\times$ store type & 2 & 0.755 & 0.66 & 0.5220 \\
Store name (store type) & 2 & 10.167 & 8.90 & $\mathbf{0 . 0 0 0 6}$ \\
Region $\times$ store name (store & 4 & 0.392 & 0.34 & 0.8473 \\
$\quad$ type) & & & & \\
Warmer Scenario & & & & \\
Region & 2 & 1.305 & 1.05 & 0.3576 \\
Store type & 1 & 1.283 & 1.04 & 0.3146 \\
Region $\times$ store type & 2 & 1.195 & 0.97 & 0.3892 \\
Store name (store type) & 2 & 53.259 & 43.02 & $<\mathbf{0 . 0 0 0 1}$ \\
Region $\times$ store name (store & 4 & 3.635 & 2.94 & $\mathbf{0 . 0 3 1 5}$ \\
$\quad$ type) & & & & \\
\hline
\end{tabular}

The dependent variable is the number of potentially invasive non-native species for sale at each store. 'Region' is Delta, East Bay, or Peninsula; 'Store Type' is Chain or Independent; 'Store Name' refers to Independents or individual chain stores (General Discount Chain, Pet Chain A, or Pet Chain B), and is nested within Store Type

(Table 3). Results were similar when adjusting for inventory size (Table 4, Fig. 3).

In the Warmer Scenario, there was no difference between chain and independent stores $\left(\mathrm{F}_{1,42}=1.04\right.$, $p=0.3146$ ) (Table 3), although when considering individual chain stores, the General Discount Chain carried significantly fewer potential invaders than independent stores and Pet Chains A and B (Fig. 3). When adjusting for store inventory size, chain and independent stores again were not significantly different (Table 4), but when considering the individual chain stores (along with independent stores as a group), Pet Chain B carried significantly more potential invaders than the General Discount Chain and Pet Chain A, while independent stores were not significantly different from any other group.

Significant interactions between region and store name in both the ANOVA and ANCOVA (using store inventory size as a covariate) for the Warmer Scenario suggest that there were differences among local regions in terms of the number of potential invaders found in a particular kind of store, and that these differences were not due to store inventory size (Tables 3 and 4).

A greater proportion of fish taxa sold in chain stores were identifiable to species level compared to independent stores $\left(F_{1,42}=49.29, p<0.0001\right)$. In addition, a greater percentage of fish species were correctly labeled in chain stores versus independent stores $\left(\mathrm{F}_{1,21}=5.35, p=0.0310\right)$ (Table 5).

Survey of store representatives

\section{Awareness}

A majority of respondents $(18 / 30=60 \%)$ had previously heard the term "invasive species", representing $66.7 \%(12 / 18)$ of independent store respondents and 
Fig. 3 Average number of Scenario (top) and Warmer Scenario (bottom). Dots represent least squares means for each store type; whiskers indicate $95 \%$ confidence intervals potential invaders in Colder

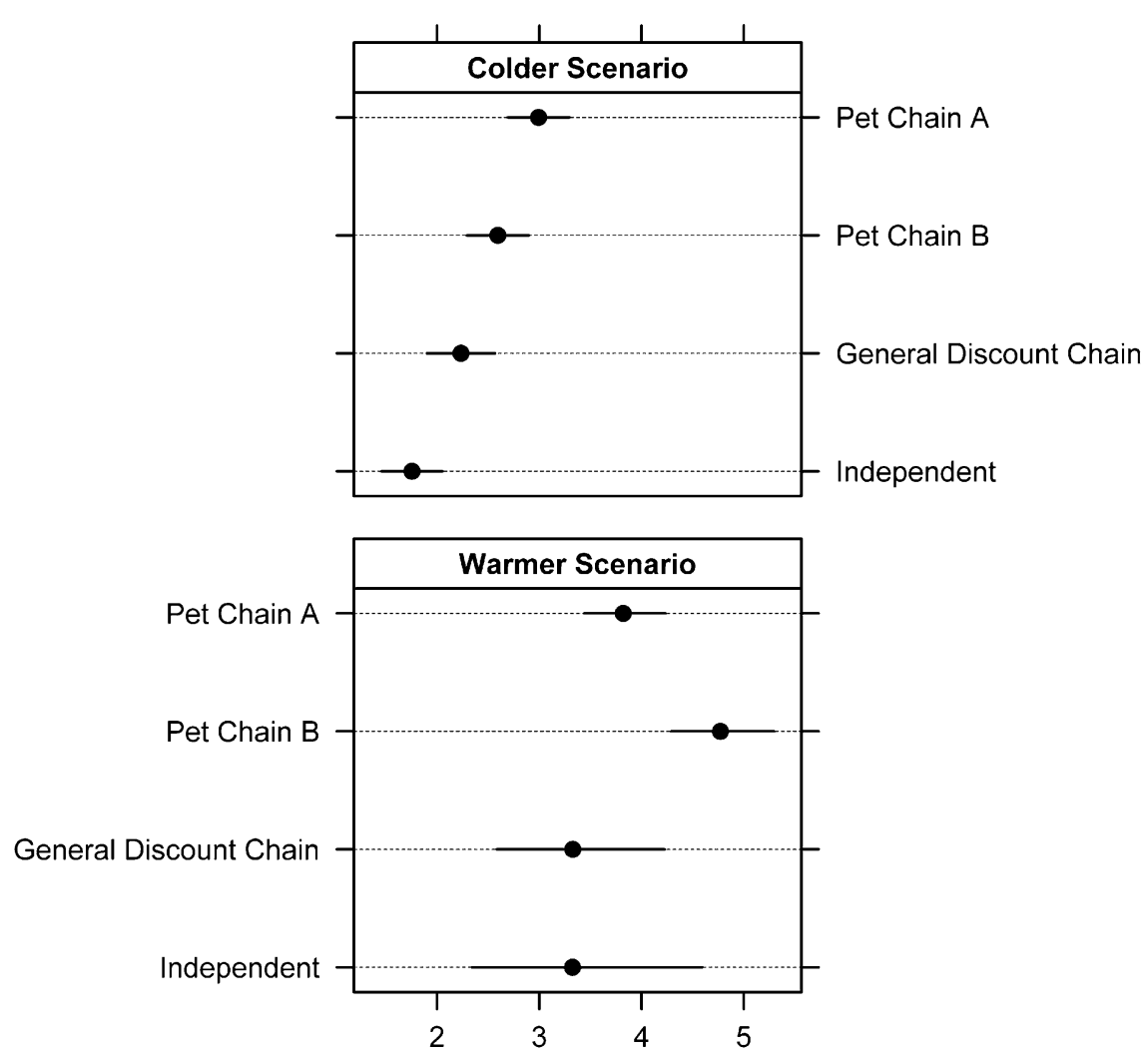

$50 \%(6 / 12)$ of chain store respondents. When given a definition of invasive species- "a species that establishes populations in an area where it is not native"90\% (27/30) of respondents reported that invasive species were an important environmental concern. Although it was not signficant at the $\alpha=0.05$ level, there was a trend that respondents who had more experience in the aquarium industry as a hobby (i.e. those who owned an aquarium or bred/traded fish) more frequently reported having heard of invasive species or having heard of aquarium pets or plants invading natural areas (owned an aquarium: Fisher's exact test, $p=0.0524$; bred/traded fish: Fisher's exact test, $p=0.0680)$. A majority $(21 / 30=70 \%)$ of store representatives in this survey reported that they thought aquarium stores sold potentially invasive fish or plants, but there was no significant difference between responses from chain store vs. independent store representatives (Fisher's exact test, $p=1.0$ ). We found no significant difference between chain store and independent store respondents in knowledge of invasive species (ANCOVA, $p=0.6978$ ).

\section{Responsibility}

Most respondents $(26 / 30=86.7 \%)$ agreed that scientists should identify which plants and animals sold in the aquarium trade are potentially invasive. Many respondents $(19 / 30=63.3 \%)$ also reported believing that the aquarium trade plays a role in the introduction of aquatic invasive species. A slightly higher percentage $(23 / 30=$ $76.7 \%$ ) reported believing that the aquarium trade has a role in the prevention of aquatic introductions. When asked to assign responsibility to specific stakeholder groups in the aquarium trade, including the aquarium industry, consumers, government, and scientists, chain store respondents were significantly more likely than independent store respondents to assign responsibility for preventing invasions to industry stakeholders (ANOVA, $p=0.0280$ ). Examination of answers to individual survey questions indicates that this result is driven by chain store representatives' assignment of more responsibility to retailers (Fisher's exact test, $p=$ 0.0378 ), while the amount of responsibility assigned to other aquarium industry sectors did not differ between 
Table 4 Weighted ANCOVA results from store survey under the Colder and Warmer Scenarios

\begin{tabular}{|c|c|c|c|c|}
\hline Source & $\mathrm{DF}$ & MS & $\mathrm{F}$ & $p$-value \\
\hline \multicolumn{5}{|l|}{ Colder Scenario } \\
\hline Region & 2 & 1.012 & 1.09 & 0.3447 \\
\hline Store type & 1 & 16.735 & 18.09 & 0.0001 \\
\hline Region $\times$ store type & 2 & 0.448 & 0.48 & 0.6198 \\
\hline Store name (store type) & 2 & 5.113 & 5.53 & 0.0075 \\
\hline $\begin{array}{l}\text { Region } \times \text { store name (store } \\
\text { type) }\end{array}$ & 4 & 0.453 & 0.49 & 0.7430 \\
\hline Store diversity & 1 & 10.064 & 10.88 & 0.0020 \\
\hline \multicolumn{5}{|l|}{ Warmer Scenario } \\
\hline Region & 2 & 1.069 & 1.26 & 0.2935 \\
\hline Store type & 1 & 0.753 & 0.89 & 0.3511 \\
\hline Region $\times$ store type & 2 & 0.236 & 0.28 & 0.7585 \\
\hline Store name (store type) & 2 & 7.416 & 8.76 & 0.0007 \\
\hline $\begin{array}{l}\text { Region } \times \text { store name (store } \\
\text { type) }\end{array}$ & 4 & 2.209 & 2.61 & 0.0493 \\
\hline Store diversity & 1 & 17.297 & 20.44 & $<0.0001$ \\
\hline \multicolumn{5}{|c|}{$\begin{array}{l}\text { The dependent variable is the percentage of potentially } \\
\text { invasive non-native species for sale at each store. 'Region' is } \\
\text { Delta, East Bay, or Peninsula; 'Store Type' is Chain or } \\
\text { Independent; 'Store Name' refers to Independents or individual } \\
\text { chain stores (General Discount Chain, Pet Chain A, or Pet } \\
\text { Chain B), and is nested within Store Type; 'Store Diversity" } \\
\text { (total number of taxa identified to species level) is treated as a } \\
\text { covariate }\end{array}$} \\
\hline
\end{tabular}

Table 5 ANOVA results from analyses of aquarium store labeling practices

\begin{tabular}{lrrrr}
\hline Source & DF & MS & F & p-value \\
\hline $\begin{array}{l}\text { Taxonomic resolution: percentage of fish taxa } \\
\quad \text { in each store }\end{array}$ \\
$\quad 2$ could be identified to species level \\
Region & 1 & 0.816 & 0.66 & 0.5226 \\
Store type & 2 & 2.296 & 1.85 & 0.1691 \\
Region $\times$ store type & 2 & 10.162 & 8.21 & $\mathbf{0 . 0 0 1 0}$ \\
Store name (store type) & 4 & 2.562 & 2.07 & 0.1020 \\
Region $\times$ store name (store & & & & \\
$\quad$ type) & & & & \\
Labeling accuracy: percentage of species present in store that \\
$\quad$ were correctly labeled & & & & \\
Region & 1 & 0.000 & 0.04 & 0.8534 \\
Store type & 1 & 0.041 & 5.35 & $\mathbf{0 . 0 3 1 0}$ \\
Region $\times$ store type & 1 & 0.000 & 0.00 & 0.9685 \\
Store name (store type) & 2 & 0.013 & 1.71 & 0.2053 \\
Region $\times$ store name (store & 2 & 0.000 & 0.06 & 0.9375 \\
$\quad$ type) & & & & \\
\hline
\end{tabular}

store types. Interestingly, a greater percentage of chain store respondents held sales associate or equivalent positions without managerial responsibility, as compared to independent store respondents (Fisher's exact test, $p<0.001$ ).

Willingness to take preventative action

Nearly all respondents $(29 / 30=96.7 \%)$ reported that customers have asked them what to do with unwanted fish, and a majority $(24 / 30=80 \%)$ of store representatives reported that they would be willing to sell different fish species in place of fish known to pose an invasion risk. Willingness to sell alternative species did not differ significantly among store types (Fisher's exact test, $p=0.6372$ ).

\section{Discussion}

Our store survey results indicate that aquarium stores in the San Francisco Bay-Delta region sell as many as 27 fish species that could potentially survive if released into Bay-Delta waters, underscoring the significance of the aquarium trade as a potential vector for non-native species introductions. While this is a small number compared to the total number of fish species identified during the survey (867 taxa identified to species level), we caution that this does not mean the risk is low. First, many of the species listed as potential invaders are among the most commonly-stocked species in the industry, and are likely sold in high volumes. Second, given global warming trends, the occurrence of warm water refugia in the region, and imperfect knowledge of fish species' lower temperature tolerances, we suggest that our Colder Scenario analysis likely underestimates the number of potentially invasive fish species available for sale in the Bay-Delta region. For example, the Dojo loach (Misgurnus anguillicaudatus) was found to be a potential invader in the Bay-Delta region only in our Warmer Scenario (minimum temperature $12^{\circ} \mathrm{C}$ ) due to its listed $10^{\circ} \mathrm{C}$ minimum temperature in FishBase (Froese and Pauly 2005). In contrast, Rixon et al. (2005) used a more restrictive minimum temperature criterion of $5.5^{\circ} \mathrm{C}$ for the Great Lakes, yet listed the Dojo loach as a likely invader there. In fact, the 
Dojo loach is already established near the Great Lakes in Michigan's Shiawassee River system, and has been documented to survive water temperatures as low as $2^{\circ} \mathrm{C}$, which meets our Colder Scenario criteria (Schultz 1960; Logan et al. 1996). Finally, our analysis examines a snapshot of the species stocked in Bay-Delta aquarium stores during one 6-month time period and does not consider all species that may be part of the aquarium trade in this area, or in the future. Querying Fishbase (Froese and Pauly 2005) for species associated with the aquarium industry returns an additional 187 saltwater and 100 freshwater fish species that were not found in our inventory but which could survive Warmer Scenario conditions.

In contrast, our Warmer Scenario may overpredict the number of potential invaders, especially for saltwater fish, as the available temperature tolerance data for these fish are much less precise than for freshwater fish. This analysis may therefore include some species that are unlikely to be able to invade the Bay-Delta in today's climate. From a riskassessment standpoint aimed at reducing the number of successful invasions, however, use of the Warmer Scenario results as a guide for management would more effectively lower invasion risk than using the Colder Scenario results. Improved estimations of invasion risk will require more accurate data describing both environmental characteristics of recipient areas, including potential refugia, as well as physiological requirements of aquarium species, especially saltwater species. Meanwhile, the Bay-Delta is likely to experience warming over the next 50-100 years due to global climate change (Hayhoe et al. 2004), potentially increasing the hospitability of this system to nonnative aquarium species, many of which are from more tropical climes.

Significantly, the risk posed by potentially invasive aquarium fish species in the Bay-Delta is not evenly distributed across the industry. In our Colder Scenario, chain store inventories contained a significantly greater number of potentially invasive species compared to independent store inventories. This pattern is driven entirely by freshwater fish inventories, due in part to the fact that compared to independent stores, chain stores generally carried a much smaller percentage of saltwater fish. This pattern in store inventory diversity may exist because chain stores likely cater to a more general clientele than the more hobbyist-focused independent stores, and freshwater fish are likely to appeal to a broader clientele because they tend to be less expensive and easier to keep than saltwater fish (Chang et al. pers. obs.). In addition, since the chain store business model revolves around lower prices and high volume (Spector 2004), these stores' inventories might emphasize species that best survive the rigors of capture, transport, and stocking, traits also conducive to survival if released into a local waterway. However, these risks might be mitigated by clear and accurate labeling of fish species for sale and a high level of employee knowledge regarding invasive species.

In fact, while chain store inventories consistently contained a greater number of species identified by the Colder Scenario that could potentially invade the Bay-Delta, current practices that might mitigate these risks were also more widespread in chain stores than in independent stores. Specifically, labeling practices in chain stores were consistently better than in independent stores, and chain store inventories were more limited and generally contained easily identifiable fish. Independent stores, in contrast, had wideranging and variable inventories as well as relatively less well-labeled fish.

Our results also suggest that chain store representatives may be better positioned to mitigate invasion risk through customer assistance and interaction. Effective mitigation by these means requires not only that an employee be aware of invasive species issues but also that he or she recognize his or her own ability to help counteract any risk posed by a particular fish being sold. Our phone survey results indicate that $60 \%$ of all respondents had heard of the term "invasive species." While $90 \%$ of all respondents considered invasive species to be a concern, independent store respondents were significantly less likely than chain store respondents to consider it the retailer's responsibility to take action regarding invasive species. However, differences between respondents from independent and chain stores may well be confounded with differences in the respondent's level of authority in the store; on average, independent store respondents had a significantly greater level of authority compared to chain store respondents. The majority of independent store respondents had managerial-level duties, and many 
were store owners, whereas most of the chain store respondents worked at sales associates or equivalent lower-level positions.

Finally, and most hopefully, a majority of both independent and chain store respondents indicated that they would be willing to sell a different species in place of one that might pose an invasion risk. This positive result suggests that some biological invasions may be avoided if aquarium industry representatives are consulted to identify and make available for sale alternative species that pose a lesser threat. The horticulture industry, which plays a similar role to the aquarium trade in terrestrial invasions, has successfully collaborated with managers to create voluntary codes of conduct to reduce risks posed by non-native species (Baskin 2002). Although awareness of these codes remains the major hurdle to their adoption (Burt et al. 2007), our results indicate that similar programs in the aquarium trade may have a reasonable likelihood of success.

Suggested research and management actions

We suggest two key management actions to reduce the overall risk of invasion via the aquarium trade. The first is to implement programs to enhance invasive species awareness and education among store representatives, focusing especially on higherlevel management at both chain and independent stores. These education initiatives would increase the ability of store employees to advise customers on the risks of their purchases and would complement general consumer education programs regarding invasive species. Education has been a key factor in encouraging the adoption of risk-lowering behavior in other industries (Burt et al. 2007), but changes to store inventories and policies often require action at the managerial level. Our results also indicate that education might have the greatest impact at this level, since employees in managerial positions were less likely to report that they believed retailers bear responsibility for preventing aquatic invasions.

Second, we recommend improving fish labeling practices, particularly in independent stores; compared to chain stores, a relatively greater proportion of fish in independent stores were mislabeled or unlabeled. In part, this reflects chain stores' greater focus on freshwater species, which are generally better described (Wabnitz et al. 2003). In independent stores, employee expertise might sometimes substitute for less thorough labeling practices, but clear and accurate identification of fish for sale is still key to informing consumers about the potential risks of their purchases. We further suggest that readily available information on key life history traits (maximum size, growth rate, aggressiveness, etc.) would help consumers avoid buying fish that wind up as unwanted pets and which may be at higher risk for inappropriate disposal into local waterways (e.g., Crossman and Cudmore 1999). This information is often available on labels used in chain stores (Chang et al., pers. obs.) Such information would ideally be complemented by warnings to customers about the potential hazards of releasing pets, which we observed at just 1 out of the 54 stores we visited during the course of this study. At that particular store, the information provided was from a commercial pet industry campaign, Habitattitude ${ }^{\mathrm{TM}}$.

Further research is needed to determine which of the potentially invasive species identified by our store inventory are most likely to be released by consumers and what, if any, significant ecological impacts they might have. The most threatening of these species could then be targets for aquarium store representative and consumer education initiatives. Effort also could be directed toward finding alternative, less potentially-invasive species, since our results indicate that people working in the aquarium trade may be willing to substitute less risky species for those demonstrated to be potentially invasive. While the relatively low response rate $(26.3 \%)$ of our telephone survey could be interpreted as a lack of willingness to engage with the issue of invasive species, we argue that this more likely reflects a general lack of willingness to participate in telephone surveys, especially since $100 \%$ of the stores we visited in person allowed us to conduct inventories. Future studies might consider interviewing store representatives in person or distributing printed survey forms to increase response rates.

In assessing the invasion risk posed by the aquarium fish trade in the Bay-Delta region, our approach considered the interaction of specific local factors: environmental parameters, species availability patterns, and awareness and attitudes of trade workers. As such, our specific conclusions should not be extrapolated beyond the region we studied, but instead studies similar to our own should be repeated in as many regions as possible. Work along these 
lines has been attempted in Florida (Semmens et al. 2004) and the Great Lakes (Rixon et al. 2005), but other regions remain less well studied. Perhaps the most fruitful approach would be to combine the techniques used in this study with the complementary methods used by Cohen et al. (2007) to examine aquarium plant releases in the St. Lawrence Seaway. Our study determined which species were available for sale in our local region, assessed each species' likelihood of survival under local environmental conditions, determined which stores or types of stores carried more of the species identified as potential invaders, and examined industry attitudes toward invasive species. Cohen et al. (2007) more directly measured propagule pressure of aquarium plant releases by combining sales volume data for individual species with consumer surveys assessing the likelihood of various methods of release. In combination, these approaches allow a comprehensive analysis of the risk posed by an invasion vector at each major phase of the introduction process, from propagule delivery to survival and establishment, while the integration of sociological information points the way to the most productive targets for management action.

Acknowledgments We thank S. Williams, P. Moyle, and J. Drake for their critical comments on the manuscript, C. Hom, S. Strauss, and R. Grosberg for crucial suggestions and support, $\mathrm{N}$. Willits for keen statistical guidance, the aquarium store representatives, and M. Lubell, M. Meyers, H. Crosson, and F. Chapman for expert advice. We thank the California Spatial Infomation Library (CaSIL) for making available geographic data, originally collected by the USGS, which we used to make Fig. 1. Figure 3 was created using R (R Development Core Team 2008). This project was funded by NSF-DGE\#0114432, the UC Davis Biological Invasions IGERT.

Open Access This article is distributed under the terms of the Creative Commons Attribution Noncommercial License which permits any noncommercial use, distribution, and reproduction in any medium, provided the original author(s) and source are credited.

\section{References}

Axelrod HR, Burgess WE, Pronek N et al (1995) Freshwater mini-atlas. T.F.H. Publications, Neptune City

Baskin Y (2002) The greening of horticulture: new codes of conduct aim to curb plant invasions. Bioscience 52:464-471. doi: 10.1641/0006-3568(2002)052[0464:TGOHNC]2.0.CO;2
Burgess WE (2000) Burgess's atlas of marine aquarium fishes. T.F.H. Publications, Neptune City

Burt JW, Muir AA, Piovia-Scott J et al (2007) Preventing horticultural introductions of invasive plants: potential efficacy of voluntary initiatives. Biol Invasions 9:909923. doi:10.1007/s10530-007-9090-4

Chapin FS, Zavaleta ES, Eviner VT et al (2000) Consequences of changing biodiversity. Nature 405:234-242. doi: $10.1038 / 35012241$

Chapman FA, Fitz-Coy SA, Thunberg EM et al (1997) United States of America trade in ornamental fish. J World Aquacult Soc 28:1-10

Cohen AN, Carlton JT (1995) Nonindigenous aquatic species in a United States estuary: a case study of the biological invasions of the San Francisco Bay and Delta. Report for the United States Fish and Wildlife Service, Washington, D.C., and the National Sea Grant College Program, Connecticut Sea Grant, NTIS Report Number PB96$166525,246 \mathrm{pp}$

Cohen J, Mirotchnick N, Leung B (2007) Thousands introduced annually: the aquarium pathway for non-indigenous plants to the St. Lawrence Seaway. Front Ecol Environ 5:528-532. doi:10.1890/1540-9295(2007)5[528:TIATAP] 2.0.CO; 2

Conomos TJ (1979) Properties and circulation of San Francisco Bay waters. In: Conomos TJ (ed) San Francisco Bay: the urbanized estuary. Pacific Division of the American Association for the Advancement of Science, San Francisco, pp 47-84

Crossman EJ, Cudmore BC (1999) Summary of North America fish introductions through the aquarium/horticulture trade. In: Claudi R, Leach JH (eds) Nonindigenous freshwater organisms: vectors, biology and impacts. Lewis Publishers, Boca Raton, pp 129-134

Froese R, Pauly D (eds) (2005) FishBase. World Wide Web electronic publication. www.fishbase.org

Fuller PL (2003) Freshwater aquatic vertebrate introductions in the United States: Patterns and pathways. In: Ruiz GM, JT Carlton (eds) Invasive species: vectors and management strategies. Island Press, pp 123-152, 518 pp

Hayhoe KD, Cayan D, Field CB et al (2004) Emissions pathways, climate change, and impacts on California. Proc Natl Acad Sci USA 101:12422-12427. doi:10.1073/pnas.0404500101

Jenkins PT (1996) Free trade and exotic species introductions. Conserv Biol 10:300-302. doi:10.1046/j.1523-1739.1996. 10010300.x

Levine JM, D'Antonio CM (2003) Forecasting biological invasions with increasing international trade. Conserv Biol 17:322-326. doi:10.1046/j.1523-1739.2003.02038.x

Logan DJ, Bibles EL, Markle DF (1996) Recent collections of exotic aquarium fishes in the freshwaters of Oregon and thermal tolerance of oriental weatherfish and pirapatinga. Calif Fish Game 82:66-80

Lotze HK, Lenihan HS, Bourque BJ et al (2006) Depletion, degradation, and recovery potential of estuaries and coastal seas. Science 312:1806-1809. doi:10.1126/science. 1128035

Moyle PB (2002) Inland fishes of California. University of California Press, $517 \mathrm{pp}$

Padilla DK, Williams SL (2004) Beyond ballast water: aquarium and ornamental trades as sources of invasive 
species in aquatic ecosystems. Front Ecol Environ 2: $131-138$

R Development Core Team (2008) R: A language and environment for statistical computing. $\mathrm{R}$ Foundation for Statistical Computing, Vienna

Rixon CAM, Duggan IC, Bergeron NMN et al (2005) Invasion risks posed by the aquarium trade and live fish markets on the Laurentian Great Lakes. Biodivers Conserv 14:13651381. doi:10.1007/s10531-004-9663-9

Ruiz GM, Carlton JT, Grosholz ED et al (1997) Global invasions of marine and estuarine habitats by non-indigenous species: mechanisms, extent, and consequences. Am Zool 37:621-632

Sala OE, Chapin FS 3rd, Armesto JJ et al (2000) Biodiversityglobal biodiversity scenarios for the year 2100. Science 287:1770-1774. doi:10.1126/science.287.5459.1770

SAS Institute Inc. (2005) Statistical analysis systems (version 9.1.2). SAS Institute, Cary

Schultz EE (1960) Establishment and early dispersal of a loach, Misgurnus anguillicaudatus (Cantor), in Michigan. Trans Am Fish Soc 89:376-377. doi:10.1577/1548-8659 (1960)89[376:EAEDOA]2.0.CO;2

Semmens BX, Buhle ER, Salomon AK, Pattengill-Semmens CV (2004) A hotspot of non-native marine fishes: evidence for the aquarium trade as an invasion pathway. Mar Ecol Prog Ser 266:239-244. doi:10.3354/meps266239

Siguan MAR (2003) Pathways of biological invasions of marine plants. In: Ruiz GM, JT Carlton (eds) Invasive species: vectors and management strategies. Island Press, pp. 183-227, 518 pp

Spector R (2004) Category killers: the retail revolution and its impact on consumer culture. Harvard Business School Press, $272 \mathrm{pp}$

Tukey JW (1962) The future of data analysis. Ann Math Stat 33:1-67. doi:10.1214/aoms/1177704711

USGS (2006) Water Quality of San Francisco Bay. Website: http://sfbay.wr.usgs.gov/access/wqdata. Cited August 12, 2006

Verizon (2004) Verizon SuperPages.com. http://www.superpages. com/. Cited 1 Nov 2004

Wabnitz C, Taylor M, Green E, Razak T (2003) From ocean to aquarium. United Nations Environment ProgrammeWorld Conservation Monitoring Centre, Cambridge

Worm B, Barbier EB, Beaumont N, Duffy JE et al (2006) Impacts of biodiversity loss on ocean ecosystem services. Science 314:787-790. doi:10.1126/science.1132294

Yahoo! (2004) Yahoo! Yellow Pages. http://www.yahoo.com/. Cited 1 Nov 2004. 